\begin{tabular}{l} 
Sharif University of Technology \\
Scientia Iranica \\
SCIENTIA \\
IRAN \\
Thansactions A: Civil Engineering \\
\hline
\end{tabular}

\title{
Static performance of geosynthetic reinforced soil walls with peripheral soil-cement mixtures
}

\author{
M. Derakhshandi ${ }^{a, *}$, Gh. Rahmati ${ }^{\mathrm{b}}$, and M. Sadjadi ${ }^{\mathrm{a}}$ \\ a. Department of Civil Engineering, Science and Research Branch, Islamic Azad University, Tehran, Iran. \\ b. Department of Civil Engineering, Arak University, Arak, Iran.
}

Received 11 May 2017; received in revised form 2 January 2018; accepted 22 October 2018

\section{KEYWORDS \\ Geogrid; \\ Reinforced retaining \\ walls; \\ Cement-treated soil; \\ Numerical model; \\ Parametric analysis.}

\begin{abstract}
Recently, much effort has been devoted to improving the performance of geosynthetic reinforced walls under various stress conditions. In this research, the effect of using cemented mixed soil as a backfill material on the static response of Geosynthetic Reinforced Soil (GRS) walls is studied. For this, numerical models based on a finite difference code are made according to one of the Royal Military College's (RMC) fullscale test walls with the segmental facing. Different arrangements of soil reinforcement are considered in the presence of cemented sandy soil and sandy soil alone. In the cementtreated approach, each reinforcement layer is surrounded by a $30-\mathrm{cm}$ cemented sand soil. The results show that the application of cement-treated sandy soil decreases the maximum deformation of the wall by as much as $75 \%$ compared to the cases where untreated sandy soil is used. Moreover, by applying cemented soil around reinforcements, the reinforcement forces reduce considerably. Therefore, increasing the number of reinforcement layers in the backfill will decrease the face wall deformation and the reinforcement forces, which are not cost effective in many situations. It is also suggested that the application of the cementtreated technique can be an efficient cost-saving method, compared to common GRS walls.

(C) 2020 Sharif University of Technology. All rights reserved.
\end{abstract}

\section{Introduction}

In order to improve the performance of earth structures, various techniques have been proposed up to now. In 1963, the stabilization of the soil retaining walls entered a new era by using galvanized steel strips as reinforcement. By introducing geosynthetic reinforcements in the 1980s, Geosynthetic Reinforced Soil (GRS) walls gained popularity due to several advantages such as cost effectiveness and the ability to tolerate deformation and settlement compared with

*. Corresponding author.

E-mail addresses: m-derakhshandi@srbiau.ac.ir (M.

Derakhshandi); ghazale.rahmati@gmail.com (Gh. Rahmati); mani.sadjadi@srbiau.ac.ir (M. Sadjadi)

doi: $10.24200 /$ sci. 2018.21076 the other type of soil retaining walls [1-3]. Moreover, since soil retaining walls are considered as permanent structures, the safety and serviceability during their lifetime should both be taken into account in their design. For this purpose, there are many recommendations in guidelines and provisions for evaluating the maximum horizontal deformation of reinforced soil retaining walls [4-6].

The main causes of deformation in GRS retaining walls in the absence of surcharge loading include the deformation of reinforced soil section and backfill soil, post-construction deformation, deformation due to construction defects, and deformation due to compaction and yielding of the foundation. Therefore, several studies have been carried out to assess the effects of these factors on the behavior of GRS retaining walls [7].

Time-dependent properties of reinforced soils (i.e., backfill soil creep and time-dependent properties 
of geosynthetic reinforcements) are important causes of post-construction deformation in GRS retaining walls that cannot be neglected in analysis (e.g., [1,811]). In this regard, Liu (2012) employed calibrated finite element models to study the short-term (end of construction) and long-term (10 years of creep) performances of GRS retaining walls [12]. They investigated the effects of reinforcement spacing, type of backfill soil, reinforcement stiffness, and length. The results showed that the deformation of a reinforced soil block was considerably affected by spacing and stiffness of reinforcement layers. They observed that the reinforcement length had a negligible effect on the deformation of a reinforced soil block. In addition, it was observed that lengthening the reinforcement layers led to a significant decrease in lateral displacement of the back of the reinforced soil section [11].

Other studies on the backfill material indicated that the type of soil had an important effect on the stiffness of the reinforced soil zone and consequently the active earth pressure at the back of the reinforced soil [7,13-15]. In general, it is accepted that the strength of soil or active earth pressure coefficient is more important than the soil stiffness (e.g., [7,16]). However, using reinforcements with high stiffness in a dense spacing arrangement reduces the effect of soil strength on deformation of the reinforced soil zone and, thus, soil stiffness and strength should be considered simultaneously for assessing the lateral displacement of GRS walls [17].

Recently, cement-treated soils have been developed to improve the serviceability of various GRS structures. For instance, the GRS bridge abutment with cement-treated backfill is now one of the standard soil structures for high-speed train lines. In order to evaluate the long-term performance of this type of GRS structure, especially against severe seismic loads, many investigations have been conducted based on the physical model in the laboratory and full-scale model in the field [18-24]. The results of these studies, in which cement-treated soils were used as a backfill immediately behind the GRS bridge abutment, showed that the lateral stiffness of the structure increased, resulting in a decrease in the deformation of the walls subjected to severe lateral loading. Moreover, greater integrity was observed between backfill and abutment. In addition to improving the performance of GRS walls, the application of cement-treated soil can result in a decrease in the thickness of the wall without a need to use pile foundations, which is more cost effective than common GRS walls [25].

As mentioned before, many studies have been performed on the behavior of GRS walls under operational stress conditions to optimize the performance and minimize the costs. The application of cement-treated reinforced soil can be an effective alternative to meeting these goals. However, there is no economic justification to implement this method for all projects due to the massive volume of cement required. Therefore, the objective of this study is to propose a simple method to improve the performance of GRS walls by applying a limited amount of cement adjacent to the reinforcement layers. For this purpose, the finite difference analysis is employed to investigate the efficiency and cost effectiveness of this technique, compared with common GRS walls with different reinforcement arrangements. According to previous studies carried out on the behavior of cement-treated soil, it appears that the application of cement-treated soil in reinforcement layers can improve the performance of GRS walls.

In this research, a numerical analysis is conducted on a large-scale GRS wall up to the end of construction. The numerical model is verified with the large-scale test constructed under the plane strain condition [26]. The results include the horizontal displacement of facing, and the reinforcement forces are compared with those attributed to the same wall, but with cement-treated sandy soil around the reinforcements.

\section{Numerical approach}

In this study, the finite difference code, Fast Lagrangian Analysis of Continua (FLAC) [27], is employed to investigate the plane-strain behavior of the GRS retaining walls. The numerical model is calibrated using the data presented from Royal Military College (RMC) physical models developed by Hatami and Bathurst (2005) [26]. Bathurst et al. (2001) [28] conducted three instrumented, large-scale tests to explore the performance of GRS segmental walls under working stress. In the following section, the physical model test is described briefly.

\subsection{The RMC physical model test description}

A modular block (segmental) GRS retaining wall, which is $3.6 \mathrm{~m}$ high, with a target-facing batter of $8^{\circ}$ from the vertical is constructed on a rigid foundation. The wall with six polypropylene (PP) geogrid reinforcement layers is constructed according to the AASHTO standard requirements. Accordingly, the spacing between reinforcement layers is $0.6 \mathrm{~m}$, and the ratio of the length of reinforcement to the height of the wall $(L / H)$ is 0.7 . Moreover, through mechanical connections, the reinforcement layers are rigidly attached to the facing (see Figure 1).

A discrete column of solid concrete blocks is employed as the wall facing. Each concrete unit is $20 \mathrm{~kg}$ (300 $\mathrm{mm}$ wide, $150 \mathrm{~mm}$ high, and $200 \mathrm{~mm}$ long). The poorly graded sand soil (Unified Soil Classification SP) is used as backfill with $D_{50}=0.34 \mathrm{~mm}$, coefficient of curvature $C c=2.25$, and coefficient of uniformity $C u=1.09$. 


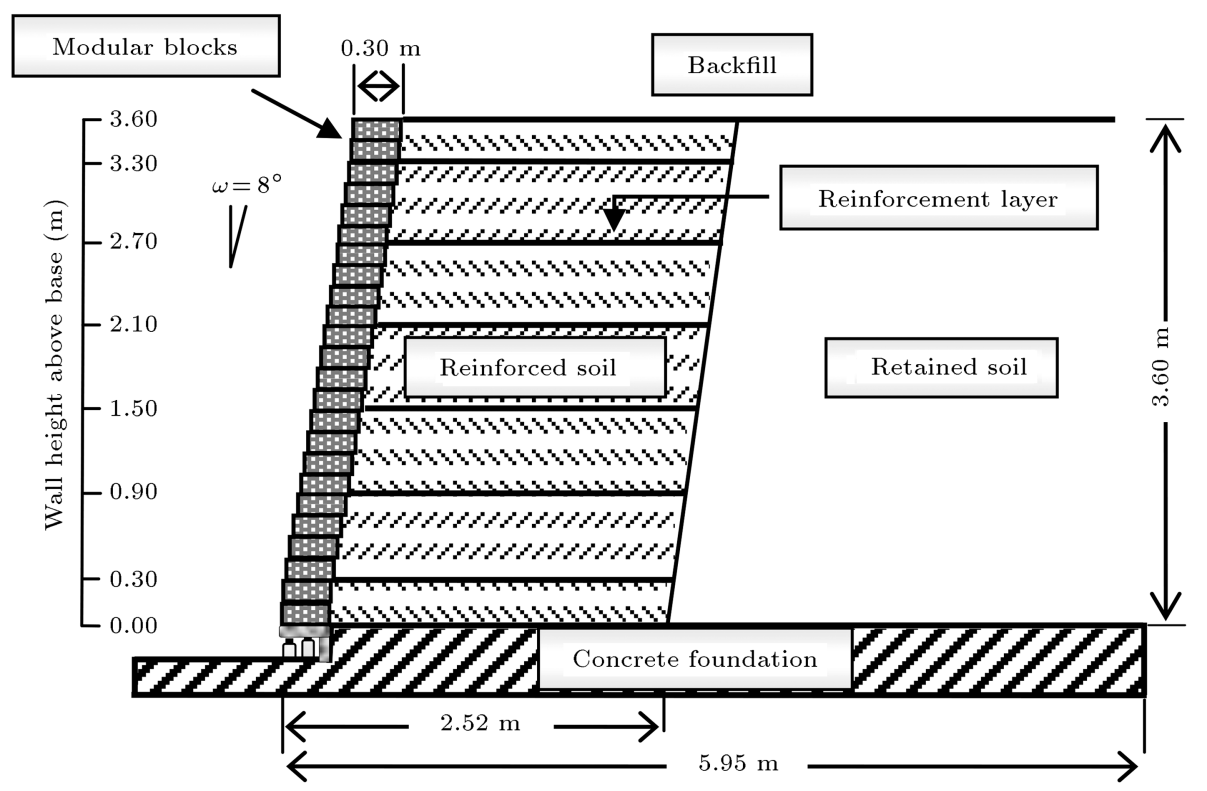

Figure 1. Cross-section of segmental reinforced soil retaining wall with Royal Military College's (RMC) physical models utilized for the calibration of the numerical model.

\subsection{Finite-difference procedure and model}

The FLAC 2D program [27] is used to simulate the plane-strain behavior of the GRS model test. The numerical procedure includes modeling the backfill, facing modular blocks and reinforcement layers, and specifying the characteristics of interfaces and boundaries. It should be noted that the stage-construction procedure is considered in the simulation for placing each soil layer, course of blocks, and geogrid reinforcement layer.

\subsection{Modeling of backfill soil}

The continuum zone is utilized to simulate the backfill soil as a homogeneous, isotropic and nonlinear elastoplastic material with the Mohr-Coulomb failure criterion and dilation angle. By using the stress-dependent hyperbolic constitutive model [29], a nonlinear elastic behavior is considered for the backfill. This constitutive model is implemented using the FISH language. In this hyperbolic model, the tangent elastic modulus,
$E_{(t)}$, the bulk modulus, $B$, and the tangent Poisson's ratio, $\nu_{(t)}$, of soil are calculated as follows:

$$
\begin{aligned}
& E_{(t)}=\left[1-\frac{R_{f} \times\left(\sigma_{1}-\sigma_{3}\right)}{\left(\sigma_{1}-\sigma_{3}\right)_{f}}\right]^{2} K_{e} \times P_{a}\left(\sigma_{3} / P_{a}\right)^{n}, \\
& B=K_{b} \times P_{a}\left(\sigma_{3} / P_{a}\right)^{m}, \\
& \nu_{(t)}=0.5-\frac{E_{t}}{6 B}, \quad 0<\nu_{t}<0.49,
\end{aligned}
$$

where $K_{e}$ is the elastic modulus number; $\left(\sigma_{1}-\sigma_{3}\right)_{f}$ is the deviatoric stress at failure; $R_{f}$ is the failure ratio; $\sigma_{1}$ and $\sigma_{3}$ are major and minor principal stresses,respectively; $n$ is the elastic modulus exponent; $K_{b}$ and $m$ are the bulk modulus number and bulk modulus exponent, respectively; $P_{a}$ is the atmospheric pressure. The properties of the backfill material are listed in Table 1.

Table 1. Backfill soil properties [26].

\begin{tabular}{lcc}
\hline Hyperbolic model parameters & $K_{e}$ & 1150 \\
& $K_{b}$ & 575 \\
& $R_{f}$ & 0.86 \\
$K_{u r}{ }^{*}$ & 1380 \\
& $n$ & 0.5 \\
& $m$ & 0.5 \\
Strength properties & $\varphi\left(^{\circ}\right)$ & 44 \\
& $c(\mathrm{kPa})$ & 1 \\
& $\Psi\left(^{\circ}\right)$ & 11 \\
Unit weight & $\gamma\left(\mathrm{kN} / \mathrm{m}^{3}\right)$ & 16.8 \\
${ }^{*}$ Unloading-reloding modulus number assumed to be $1.2 \times K_{e}$ for compacted sand [29].
\end{tabular}


Table 2. The properties of cement-treated soil [32].

\begin{tabular}{lc}
\hline Young's modulus, $E(\mathrm{MPa})$ & 200 \\
Cohesion, $C(\mathrm{kPa})$ & 200 \\
Internal friction angle, $\Phi\left(^{\circ}\right)$ & 46 \\
Poisson's ratio, $\nu$ & 0.3 \\
\hline
\end{tabular}

It should be noted that the boundary of backfill is extended to five times the wall height to minimize the possible effect of the far-field boundary on simulation response [30]. In addition, a parametric study is conducted to study the effect of using cement-treated soil adjacent to geogrid layers on the behavior of the wall. The mechanical properties of the cemented poorly graded sand soil are chosen because of their similarity to the results of triaxial tests in the literature $[31,32]$. The cement content of the soil is considered to be $5 \%$. The mechanical properties of cement-treated soil are given in Table 2 in which $E$ is Young's modulus of cemented soil with $15 \mathrm{~cm}$ thickness on either side of reinforcement layers, which is defined by FLAC FISH programming as a hyperbolic formulation. The analysis in this part has been conducted for backfill sandy soil and backfill cemented sandy soil in different reinforcement layers.

\subsection{Modeling of reinforcement layers}

Reinforcement layers are modeled using a cable element with strain-dependent tangent tensile stiffness $J_{t}$ $(\varepsilon)$, tensile strength $T_{y}$, and no compressive strength. Cable elements are one-dimensional axial elements with elasto-plastic behavior. The soil-reinforcement interaction can be simulated by using the FLAC grout utility with zero thickness, zero cohesion, and interface friction angle of $0.75 \phi\left(\delta_{s r}\right)$. However, previous studies show that no slippage may occur between the reinforcement elements and the backfill soil under working stress conditions $[17,26,33]$. Therefore, in this study, the reinforcement structural nodes are rigidly connected to the backfill grid points. The reinforcement material properties used in numerical simulations are summarized in Table 3. Moreover, the reinforcement layers

Table 3. The reinforcement material properties [26].

\begin{tabular}{lc}
\hline$\delta_{s r}\left({ }^{\circ}\right)$ & 33 \\
$T_{y}(\mathrm{kN} / \mathrm{m})$ & 13 \\
$J_{t}(\mathrm{kN} / \mathrm{m})$ & $(119-2938) \varepsilon$ \\
\hline
\end{tabular}

are attached rigidly to the facing based on the use of mechanical connections in the model.

\subsection{Modeling of facing system}

The linear elastic continuum zones are used to model the facing wall. The nulled zones with zero thickness that include interfaces are used to divide the facing column of walls into 24 rows of concrete modular blocks. The stiffness of the facing column is determined by the values of interface shear stiffness between modular blocks obtained from the results of direct shear tests conducted in the laboratory.

\subsection{Interfaces and boundary conditions}

The interface elements between different contact surfaces and joints are simulated by linear spring-slider systems. The interface shear strength is defined by the Mohr-Coulomb failure criterion in which the shear and normal interface stiffness $\left(K_{s}\right.$ and $K_{n}$, respectively) values must be defined to control the relative interface movement. Therefore, the values of interface stiffness should be selected to match physical test results. In the numerical simulations, the boundary conditions have been defined to represent the RMC model test facilities accurately. In this regard, a fixed boundary condition is applied at numerical grid points in the $X$ direction on the backfill far-end boundary to match the bulkheads that are used at the back of the test facility. In addition, in order to simulate the concrete foundation of the RMC model test, a fixed base condition is assumed in both $X$ and $Y$ directions on the bottom of the model [26]. The interface parameters used in the current study are reported in Table 4.

Moreover, in order to consider the compaction effects in the simulations, a uniform vertical stress of $8 \mathrm{kPa}$ has been applied at each construction stage to the entire surface. Since the wall is constructed using the bottom-up approach, this vertical stress increment is removed after solving the model to equilibrium at each stage. Static analyses are conducted for identical segmental walls with different reinforcement layer arrangements. Walls are modeled with six, five, four, and three reinforcement layers at $60 \mathrm{~cm}, 75 \mathrm{~cm}$, $90 \mathrm{~cm}$, and $120 \mathrm{~cm}$ vertical distances, respectively. The schematic cross-section of the finite-difference model is shown in Figure 2.

Table 4. Interface properties [26].

\begin{tabular}{lcc}
\hline Interface properties & Soil-block & Block-block \\
\hline Friction Angle, $\delta\left(^{\circ}\right)$ & 44 & 57 \\
Dilation Angle, $\Psi\left(^{\circ}\right)$ & 11 & - \\
Cohesion, $C(\mathrm{kPa})$ & - & 46 \\
Normal Stiffness, $k_{n}\left(\mathrm{MN} \mathrm{m}^{-1} \mathrm{~m}^{-1}\right)$ & 100 & 1000 \\
Shear Stiffness, $k_{s}\left(\mathrm{MN} \mathrm{m}^{-1} \mathrm{~m}^{-1}\right)$ & 1 & 40 \\
\hline
\end{tabular}




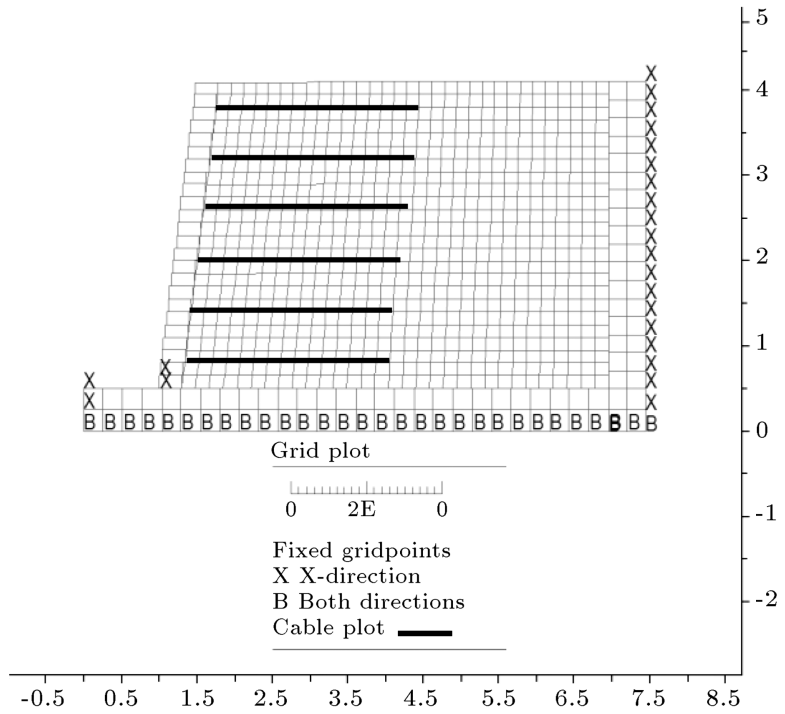

Figure 2. The finite difference model of Geosynthetic Reinforced Soil (GRS) wall with six layers at a $60-\mathrm{cm}$ vertical distance.

\subsection{Validation of finite difference procedure}

Any numerical simulation needs to be validated before analyzing the results. In the current investigation, a numerical model made by FLAC is verified against the data gathered from the RMC laboratory's physical model. More details of the physical model can be found in the study of Hatami and Bathurst (2005) [26]. The predicted horizontal displacement and connection loads of the GRS walls with six reinforcement layers at a 60$\mathrm{cm}$ vertical distance are compared with the measured identical test data. As shown in Figure 3, the results of the numerical model are in satisfactory agreement with the laboratory results.

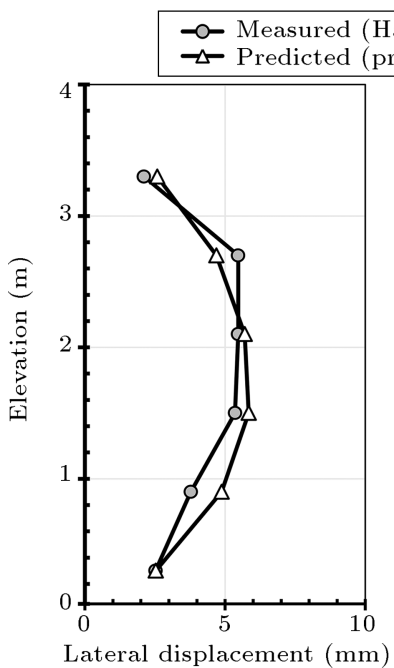

(a)

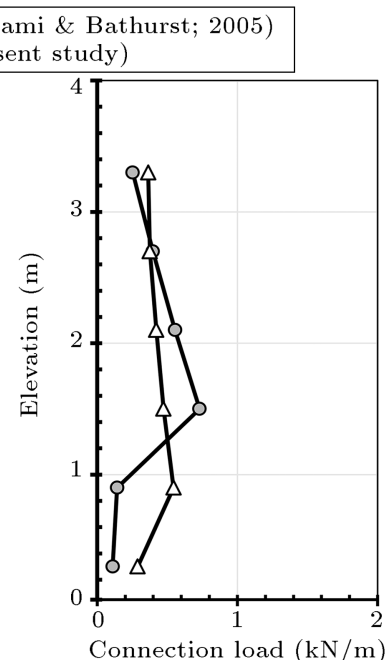

(b)
Figure 3. The validation of the finite difference procedure with Royal Military College's (RMC) physical model: (a) Relative facing displacement and (b) connection load.
It should be noted that the reported displacement value at each level in Figure 3(a) represents the magnitude of the lateral displacement of the corresponding facing block from the time of potentiometer placement to the end of construction. Hence, these plots should not be confused with the actual wall deformation profiles at the end of construction. Moreover, Figure 3(b) shows the satisfactory agreement between the calculated and measured connection loads with the exception of Reinforcement Layers 1 and 2. The same trend was seen in the numerical study of Hatami and Bathurst (2005) [26] using FLAC software in comparison with the results of the same full-scale test wall. They explained that these discrepancies might result from the local over-compaction of soil directly behind the facing units at the bottom of the walls.

\section{Results and discussion}

In the following sections, a comparison is made between the results of static analyses of segmental GRS walls and different reinforcement layer arrangements in the presence and absence of cement-treated reinforced soil. The schemes of reinforcement distribution include six, five, four, and three reinforcement layers at $60 \mathrm{~cm}$, $75 \mathrm{~cm}, 90 \mathrm{~cm}$, and $120 \mathrm{~cm}$ vertical distances, respectively. In addition, in all numerical simulations, the thickness of cement-treated soil is considered to be 15 $\mathrm{cm}$ on each side of the reinforcement layer.

\subsection{The horizontal deformation}

In this part, the horizontal deformation of GRS wall facings with different backfill conditions is presented. It should be noted that since the wall foundation is modeled as rigid and the effect of compaction efforts on wall deformation is considered at different stages of construction, the lateral displacement of the wall mainly results from deformation in the reinforced zone and the unreinforced soil zone behind the facing. The reinforcement stiffness factor $\Lambda=\frac{J}{K_{a} \gamma H S_{v}}$ can be introduced as one of the most efficient material parameters affecting the lateral deformation of GRS walls, where $J$ is the reinforcement stiffness; $K_{a}$ is the Rankin active earth pressure coefficient; $\gamma$ is the unit weight of the soil; $H$ is the wall height; $S_{v}$ is the vertical spacing between layers of reinforcement [7]. For instance, as can be observed in Figure 4(a) and (b), an increase in the number of reinforcements (i.e., increase in $\Lambda$ ) causes a decrease in the horizontal deformation of the wall for different backfill conditions. These observations confirm the efficient role of $\Lambda$ in controlling the wall deformation.

In Figure 5, the lateral displacement of GRS walls is compared for cement-treated backfill relative to the untreated backfill using the same scheme of reinforcement distribution. This figure clearly indicates 
that using cement-treated soil adjacent to the reinforcements significantly decreases the deformation of the facing. The maximum amounts of decrease in wall

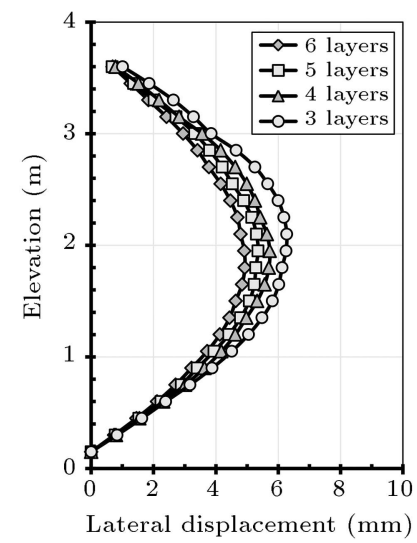

(a)

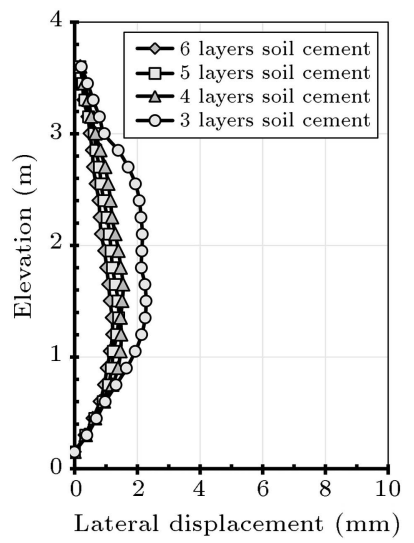

(b)
Figure 4. Horizontal deformation of Geosynthetic Reinforced Soil (GRS) wall using (a) untreated backfill soil and (b) cement-treated backfill soil.

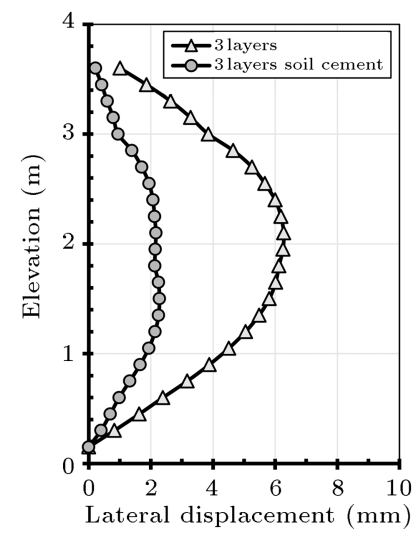

(a)

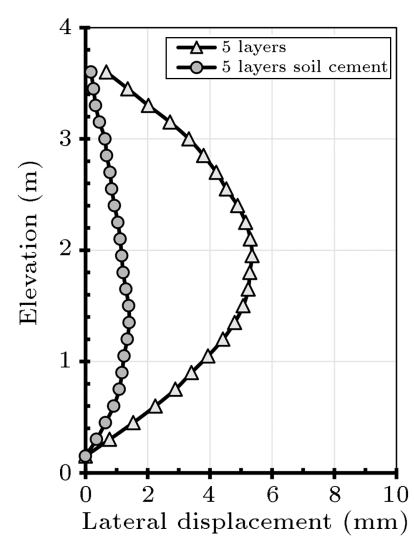

(c)

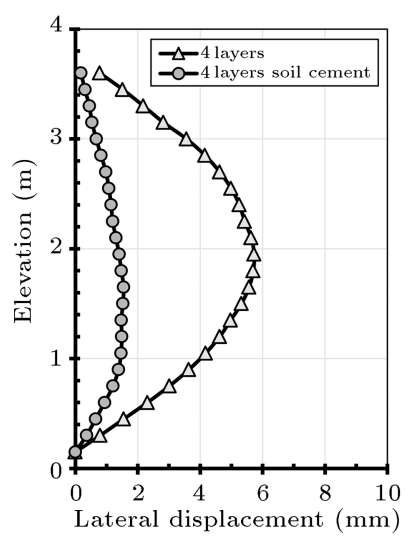

(b)

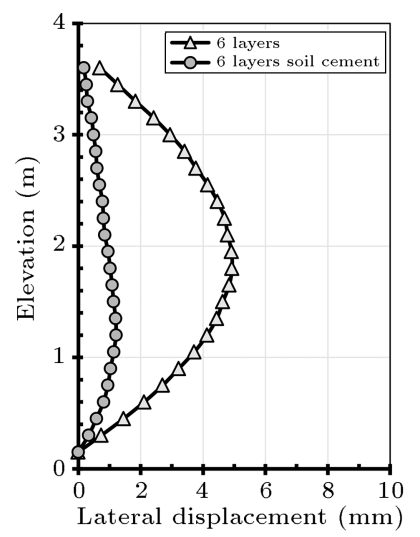

(d)
Figure 5. Comparison of horizontal deformation of Geosynthetic Reinforced Soil (GRS) wall under static condition in the presence and absence of cement-treated backfill: (a) Three reinforcement layers, (b) four reinforcement layers, (c) five reinforcement layers, and (d) six reinforcement layers. deformation along the height of the facing are presented in Table 5 .

As a result, using cement-treated backfill can be attributed to greater stiffness of the reinforced soil in the reinforced soil zone, especially in areas adjacent to the reinforcement layers. Therefore, due to strain compatibility between the reinforcement and the soil, the potential slippage at the reinforcement-soil interface becomes smaller, which decreases the reinforced soil zone deformation. Furthermore, the horizontal movement of the unreinforced soil zone behind the reinforced soil block has a considerable effect on the wall facing deformation. The amount that this source contributes to wall face displacement depends on the level at which the zero-force line intercepts the back of the reinforced soil block. The zero-force line is a theoretical line beyond which the soil does not make a significant contribution to wall face deflection. As can be observed in Figure 6, the internal friction angle of backfill soil determines the slope of the zeroforce line. Thus, the internal friction angle of backfill soil is another important parameter that affects the deformation of GRS walls [7].

The application of cement-treated soil adjacent to reinforcement layers increases the inertial friction angle of backfill soil. This makes the area of unreinforced retained fill above the zero-force line smaller. Hence, it appears that the movement of unreinforced soil behind the reinforced soil block becomes smaller, which leads to a decrease in wall deformation. Moreover, as can be seen in Figure 5, the application of cement-treated soil causes the locus of maximum deformation of the wall to move down from $H / 2$ to $H / 3$. This is also due to

Table 5. The maximum percentage of reductions in wall facing deformation using cement-treated backfill compared with untreated backfill.

\begin{tabular}{cccccc}
\hline The number of reinforcement layers & 3 & 4 & 5 & 6 \\
\cline { 1 - 5 } The reduction of facing deformation (\%) & 64 & 73 & 74 & 75 \\
\hline
\end{tabular}

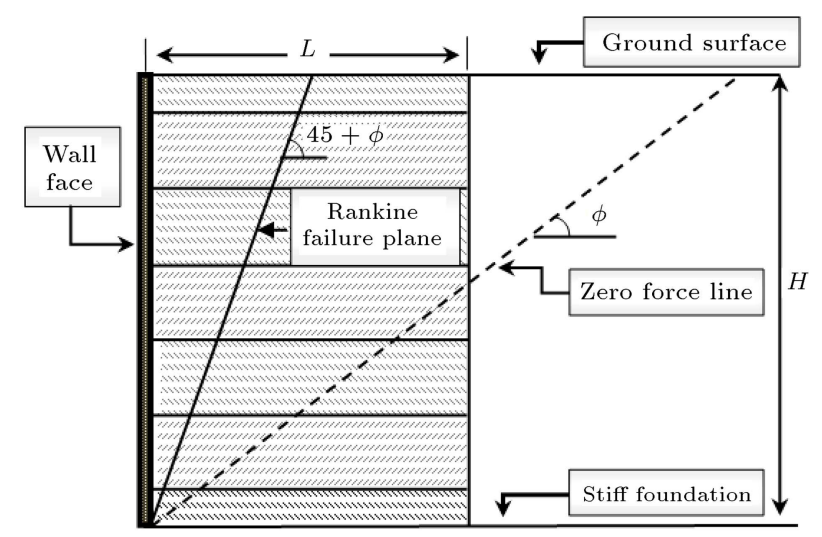

Figure 6. Schematic Geosynthetic Reinforced Soil (GRS) wall geometry and zero-force line [7]. 
Table 6. The maximum reduction in wall deformation using different reinforcement layers.

\begin{tabular}{ccc}
\hline $\begin{array}{c}\text { The number } \\
\text { of layers }\end{array}$ & The percentage of reductions \\
\cline { 2 - 3 } & $\begin{array}{c}\text { Cement-treated } \\
\text { backfill }\end{array}$ & $\begin{array}{c}\text { Untreated } \\
\text { backfill }\end{array}$ \\
\hline From 3 to 4 & 44.5 & 22 \\
From 4 to 5 & 27 & 13.5 \\
From 5 to 6 & 24.5 & 12 \\
\hline
\end{tabular}

the reduction of the unreinforced soil zone behind the reinforced soil zone, which contributes to the top wall deformation.

Table 6 presents the maximum reduction in facing displacement in the presence of the reinforcement layers. The numerical results suggest that the application of cement-treated soil results in the maximum reduction of deformation, about twice as much as the untreated soil with an increased number of reinforcement layers. This means that the application of cement-treated soil increases the effect of using the reinforcement layers on the reduction of horizontal deformation of the wall. It can also be observed that there are four reinforcement layers under both backfill soil conditions. Increasing the number of reinforcement layers beyond four does not seem to cause a significant reduction in wall deformation.

The lateral deformation of wall facing under static conditions is shown in Figure 7 for different schemes of reinforcement distribution using cementtreated backfill, compared with untreated backfill using six layers of reinforcement. According to this figure, in the presence of cement-treated soil, the deformation of the wall with the minimum number of reinforcement

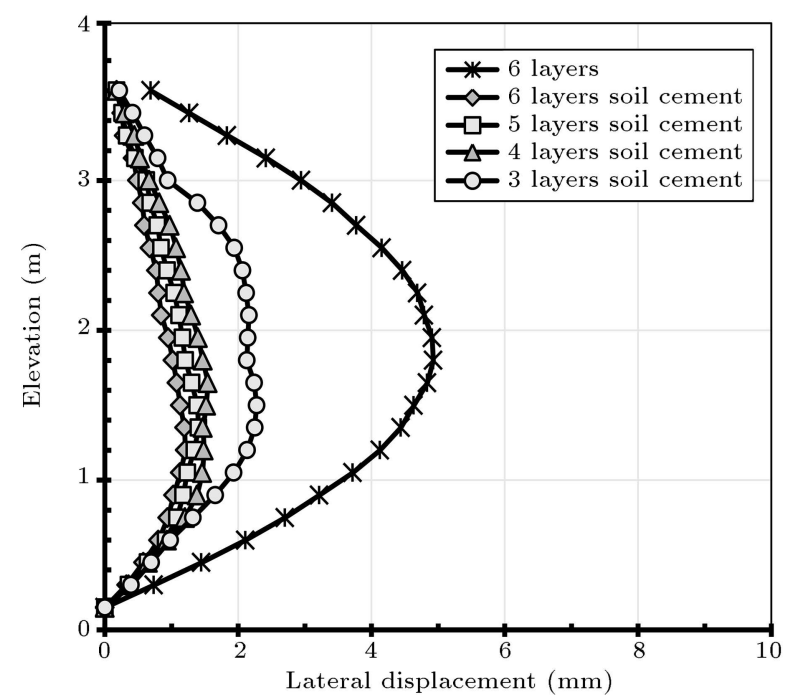

Figure 7. Comparison of the horizontal deformation of the facing wall in the presence and absence of cement-treated backfill. layers (i.e., three layers) becomes smaller than that of the wall without cement-treated soil with the maximum number of reinforcement layers (i.e., six layers). This important finding implies that the use of the recommended method in this study can decrease the number of reinforcement layers, which may be a cost-effective technique in the construction of GRS walls.

\subsection{Force distribution in the reinforcement layer}

In this section, the maximum force in the reinforcement layers along the height of the wall is compared under different backfill conditions. As illustrated in Figure 8, the application of the cement-treated soil adjacent to the reinforcement layers causes a considerable reduction in the maximum reinforcement forces.

It should be noted that the magnitude of reinforcement forces in GRS walls depends on the shear strength mobilized in the backfill soil [7]. The application of cement-treated soil increases the soilreinforcement contact efficiencies, enhancing both the shear strength of the backfill soil and the pullout resistance along the soil-reinforcement interface [34]. Therefore, a smaller force would be required in the

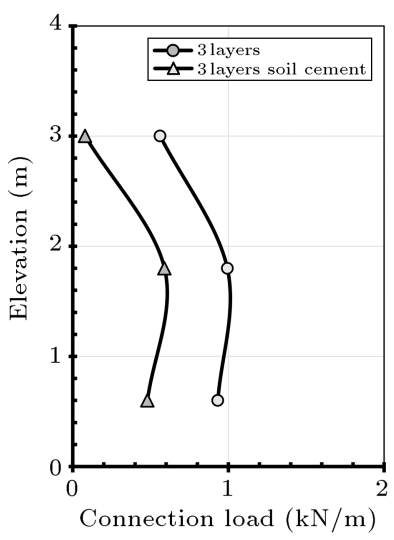

(a)

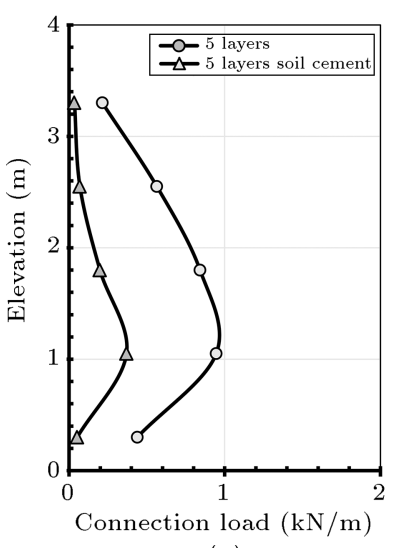

(c)

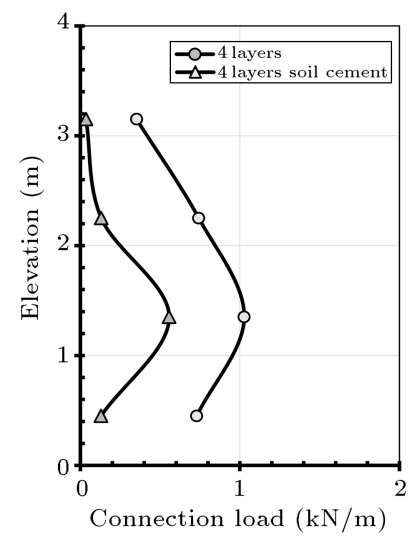

(b)

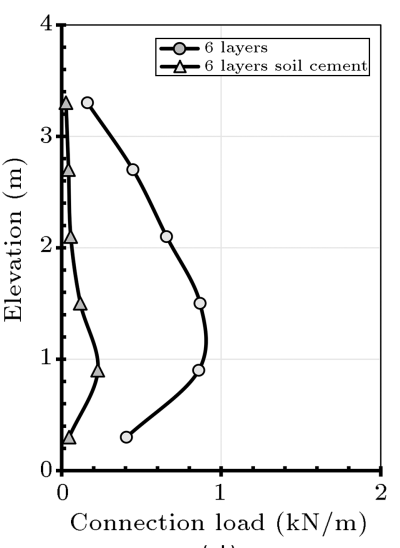

(d)
Figure 8. The maximum reinforcement force in the presence and absence of cement-treated soil: (a) Three layers, (b) four layers, (c) five layers, and (d) six layers. 
Table 7. Comparison of the maximum percentage reduction of reinforcement force due to using cement-treated soil.

\begin{tabular}{cccccccc}
\hline $\begin{array}{c}\text { The number of } \\
\text { reinforcement layers }\end{array}$ & \multicolumn{6}{c}{$\begin{array}{c}\text { The reinforcement layer number from } \\
\text { the bottom of wall }\end{array}$} \\
\cline { 2 - 8 } & $\mathbf{1}$ & $\mathbf{2}$ & $\mathbf{3}$ & $\mathbf{4}$ & $\mathbf{5}$ & $\mathbf{6}$ \\
\hline 3 & 30.94 & 40.63 & 85.81 & - & - & - \\
4 & 82.3 & 45.8 & 82.34 & 89.95 & - & - \\
5 & 88.1 & 60.95 & 76.42 & 87.6 & 83.75 & - \\
6 & 88.55 & 73.59 & 86.46 & 91.31 & 90.34 & 83.3 \\
\hline
\end{tabular}

GRS wall system to maintain equilibrium. This results in a reduction in the reinforcement maximum forces. Table 7 shows the maximum percentage reduction of reinforcement forces for different schemes of reinforcement distributions.

Figure 9 shows the distribution of forces along reinforcement layers for cement-treated and untreated backfill soil reinforced with five geogrids. It can be observed that, in the presence of cemented soil, a considerable force reduction occurs along the reinforcement layers compared with untreated reinforced soil.

Figure 10(a) and (b) demonstrate the effect of increasing the amount of reinforcement on the maximum forces of reinforcement layers. According to these figures, for both reinforced soil conditions, as the number of reinforcement layers increases, the largest magnitude of reinforcement forces decreases. This is due to an increase in $\Lambda$, which leads to a decrease in reinforcement forces. According to the numerical modeling results, the second reinforcement layer experiences a higher maximum force than the other reinforcement layers in all the cases studied.

The maximum forces in the reinforcement layers under operational conditions are shown in Figure 11 for different schemes of reinforcement distribution using cement-treated backfill against untreated backfill using six layers of reinforcement. It is clear in this figure that,
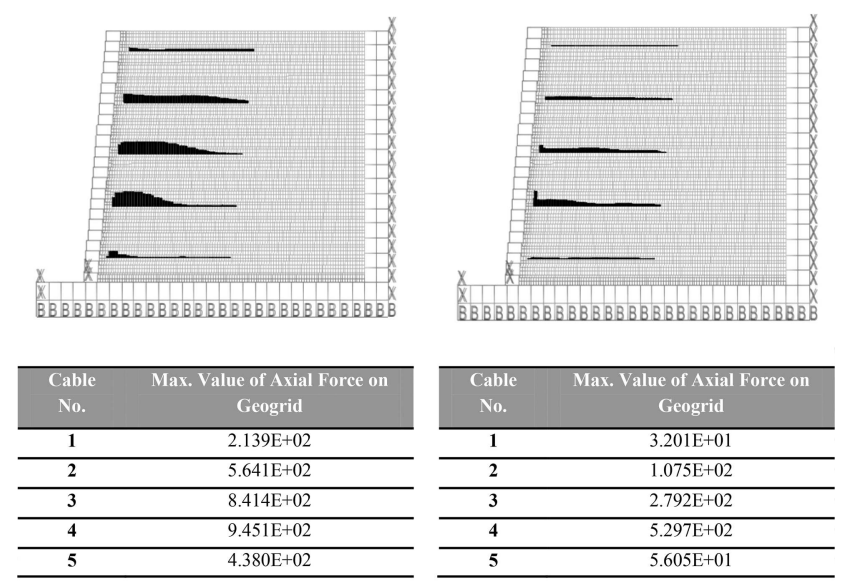

Figure 9. The variation of force distribution along 5 reinforcement layers: (a) Untreated backfill soil and (b) cement-treated backfill soil. in the presence of cement-treated soil, the maximum reinforcement forces along the height of the wall, even with the minimum number of reinforcement layers (i.e., three layers), are smaller than the untreated reinforced soil with the maximum number of reinforcement layers

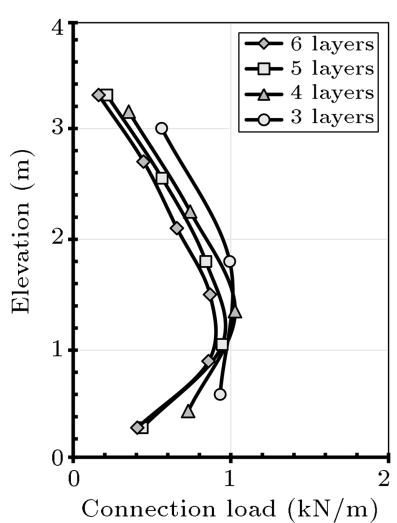

(a)

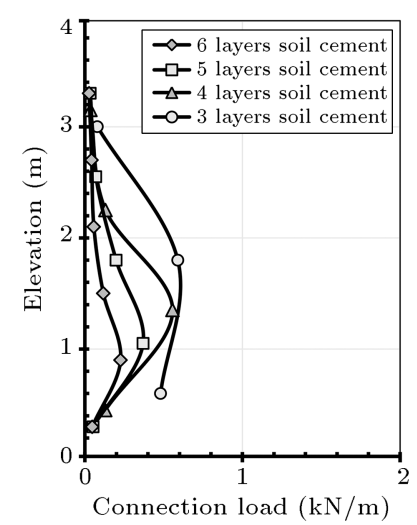

(b)
Figure 10. Comparison of the maximum magnitude of reinforcement forces with increasing the number of reinforcement layers using (a) untreated backfill soil and (b) cement-treated backfill soil.

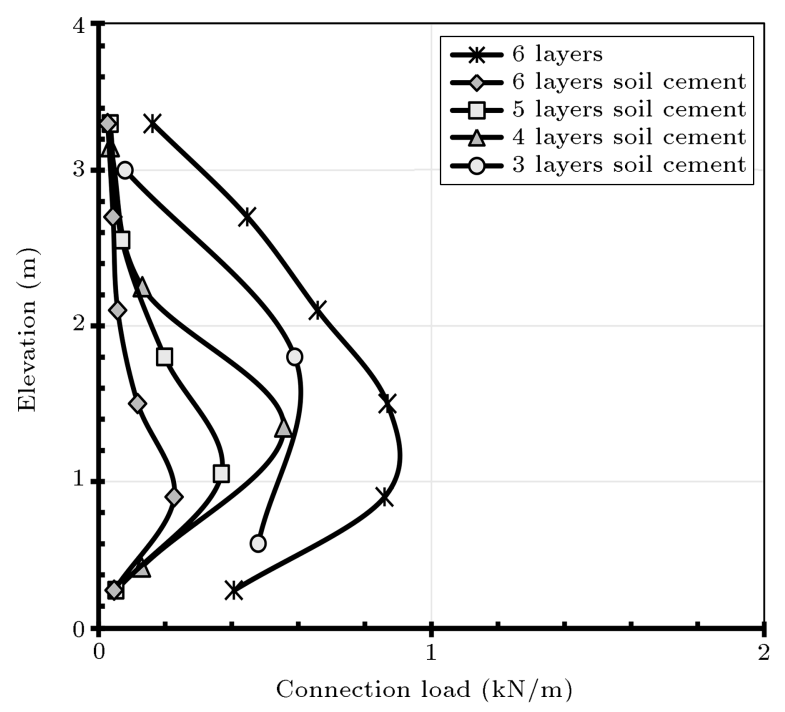

Figure 11. Comparison of the maximum reinforcement force in the presence and absence of cement-treated backfill. 
(i.e., six layers). These observations are in agreement with our previous suggestions, in which the application of cement-treated soil adjacent to the reinforcement is considered to be a cost-effective technique for constructing GRS walls.

In summary, according to the results achieved in this study, the application of the peripheral soil cement mixture can be a trustworthy method for improving the performance of GRS walls. It should be noted that this improvement technique can be more economical than typical types of GRS walls with the rectangular or trapezoidal soil cemented zone due to the reduction of cement consumption. However, it is recommended that more investigation of and comparison between these methods be done.

\section{Conclusion}

Geosynthetic Reinforced Soil (GRS) retaining walls are widely used as permanent structures in many countries. However, the safety of these walls is always the first concern in their design. In order to improve the behavior of this kind of the soil structure, various improvement methods have been recommended such as using cement-treated reinforced soil. In this paper, a numerical simulation was conducted to study the effectiveness of applying cement-treated soil with limited thickness $(30 \mathrm{~cm})$ adjacent to reinforcement layers. The most important findings of this study are summarized below:

1. Increasing the number of reinforcement layers in the presence and absence of cement-treated reinforced soil results in a decrease in wall deformation by increasing the reinforcement stiffness factor $(\Lambda)$;

2. Using cement-treated soil adjacent to reinforcement layers reduces the wall facing deformation considerably (e.g., up to $75 \%$ for a wall including six layers of reinforcement). This reduction is the result of decreasing deformation in the reinforced zone and displacement in the unreinforced soil block behind the reinforced zone;

3. Adding cement to backfill soil around the reinforcement layers changes the deformation mode of facing blocks. The maximum horizontal deformation due to the reduction of unreinforced soil behind the reinforced zone and beyond the zero-force line is lowered from $H / 2$ to $H / 3$;

4. The application of cemented soil has a significant effect on the reduction of the maximum reinforcement forces. This is caused by increasing the shear strength of backfill soil around the reinforcement layers;

5. In the presence of 30-cm cement-treated soil adjacent to the reinforcement layers, the performance of GRS walls considerably improved. This finding implies that the application of this technique can be a cost-saving construction alternative, where a large number of reinforcement layers are required.

\section{References}

1. Yang, G., Zhang, B., and Zhou, Q. "Behaviour of geogrid reinforced soil retaining wall with concreterigid facing", Geotextiles and Geomembranes, 27(5), pp. 350-356 (2009).

2. Yoo, C. and Kim, S.B. "Performance of a two-tier geosynthetic reinforced segmental retaining wall under a surcharge load: full-scale load test and 3D finite element analysis", Geotextiles and Geomembranes, 26(6), pp. $460-472$ (2008).

3. Zhang, M., Zhou, H., Javadi, A., and Wang, Z. "Experimental and theoretical investigation of strength of soil reinforced with multi-layer horizontal-vertical orthogonal elements", Geotextiles and Geomembranes, 26(1), pp. 1-13 (2008).

4. Collin, J.G., Design Manual for Segmental Retaining Walls, National Concrete Masonry Association (NCMA) (1996).

5. AASHTO, Load and Resistance Factor Design Movable Highway Bridge Design Specifications, AASHTO (2007).

6. Rogbeck, Y. and Center, N., Nordic Guidelines for Reinforced Soils and Fills, Nordic Geotechnical Societies (2005).

7. Rowe, R.K. and Ho, S. "Horizontal deformation in reinforced soil walls", Canadian Geotechnical Journal, 35(2), pp. 312-327 (1998).

8. Fannin, R. "Long-term variations of force and strain in a steep geogrid-reinforced soil slope", Geosynthetics International, 8(1), pp. 81-96 (2001).

9. Allen, T. and Bathurst, R. "Observed long-term performance of geosynthetic walls and implications for design", Geosynthetics International, 9(5-6), pp. 567606 (2002).

10. Liu, H. and Ling, H.I. "Unified elastoplasticviscoplastic bounding surface model of geosynthetics and its applications to geosynthetic reinforced soilretaining wall analysis", ASCE Journal of Engineering Mechanics, 133(7), pp. 801-815 (2007).

11. Liu, H. and Won, M.-S. "Long-term reinforcement load of geosynthetic-reinforced soil retaining walls", Journal of Geotechnical and Geoenvironmental Engineering, 135(7), pp. 875-889 (2009).

12. Liu, H. "Long-term lateral displacement of geosynthetic-reinforced soil segmental retaining walls", Geotextiles and Geomembranes, 32, pp. 18-27 (2012).

13. Helwany, S., Reardon, G., and Wu, J. "Effects of backfill on the performance of GRS retaining walls", Geotextiles and Geomembranes, 17(1), pp. 1-16 (1999). 
14. Ling, H.I. and Leshchinsky, D. "Finite element parametric study of the behavior of segmental block reinforced-soil retaining walls", Geosynthetics International, 10(3), pp. 77-94 (2003).

15. Ling, H.I., Liu, H., and Mohri, Y. "Parametric studies on the behavior of reinforced soil retaining walls under earthquake loading", Journal of Engineering Mechanics, 131(10), pp. 1056-1065 (2005).

16. Jewell, R. "Deformation calculations for reinforced soil walls", in Proc. Twelfth Int'l Conf. on Soil Mech and Found. Engr., Rio de Janeiro (1985).

17. Leshchinsky, D. and Vulova, C. "Numerical investigation of the effects of geosynthetic spacing on failure mechanisms in MSE block walls", Geosynthetics International, 8(4), pp. 343-365 (2001).

18. Watanabe, K., Tateyama, M., Yonezawa, T., Aoki, H., Tatsuoka, F., and Koseki, J. "Shaking table tests on a new type bridge abutment with geogrid-reinforced cement treated backfill in geosynthetics: State of the art-recent developments", Proceedings of the Seventh International Conference on Geosynthetics, 7-ICG, held 22-27 September 2002, Nice, France (2002).

19. Aoki, H., Yonezawa, T., Tateyama, M., Shinoda, M., and Watanabe, K. "Development of a seismic abutment with geogrid-reinforced cement-treated backfills", in Proceedings of the International Conference on Soil Mechanics and Geotechnical Engineering (2005).

20. Tatsuoka, F., Tateyama, M., Aoki, H., and Watanabe, K. "Bridge abutment made of cement-mixed gravel back-fill", Elsevier Geo-Engineering Book Series, 3, pp. 829-873 (2005)

21. Tatsuoka, F., Hirakawa, D., Nojiri, M., Aizawa, H., Tateyama, M., and Watanabe, K. "Integral bridge with geosynthetic-reinforced backfill", in Proc. First Pan American Geosynthetics Conference \& Exhibition, Cancun, Mexico (2008).

22. Munoz, H., Tatsuoka, F., Hirakawa, D., Nishikiori, H., Soma, R., Tateyama, M., and Watanabe, K. "Dynamic stability of geosynthetic-reinforced soil integral bridge", Geosynthetics International, 19(1), pp. 11-38 (2012).

23. Suga, M.N.T., Kuriyama, R., Kojima, K., and Koda, M. "A series of lateral loading test of the geosyntheticreinforced soil integral bridge", J Geosynth Eng IGS Jpn Chapter, 27, pp. 157-164 (2012).

24. Koda, M., Nonaka, T., Suga, M., Kuriyama, R., Tatetama, M., and Tatsuoka, F. "A series of lateral loading tests on a full-scale model of geosyntheticreinforced soil integral bridge", in Proc. International Symposium on Design and Practice of GeosyntheticReinforced Soil Structures (2013).

25. Yonezawa, T., Yamazaki, T., Tateyama, M., and Tatsuoka, F. "Design and construction of geosyntheticreinforced soil structures for Hokkaido high-speed train line", Transportation Geotechnics, 1(1), pp. 320 (2014).

26. Hatami, K. and Bathurst, R.J. "Development and verification of a numerical model for the analysis of geosynthetic-reinforced soil segmental walls under working stress conditions", Canadian Geotechnical Journal, 42(4), pp. 1066-1085 (2005).

27. Itasca, F.U., Fast Lagrangian Analysis of Continua, in Itasca Consulting Group Inc. Minneapolis, USA (2001).

28. Bathurst, R.J., Walters, D.L., Hatami, K., and Allen, T.M. "Full-scale performance testing and numerical modelling of reinforced soil retaining walls", In Proceedings of the 4 th International Symposium on Earth Reinforcement, IS Kyushu 2001, Fukuoka, Japan, 1416 November 2001. Edited by H., Ochiai, J., Otani, N., Yasufuku, and K., Omine. A.A. Balkema, Rotterdam, The Netherlands. 2, pp. 777-799 (2001).

29. Duncan, J.M., Wong, K.S., and Mabry, P. "Strength, stress-strain and bulk modulus parameters for finite element analyses of stresses and movements in soil masses", in Geotechnical Engineering, University of California (1980).

30. Bathurst, R.J. and Hatami, K. "Seismic response analysis of a geosynthetic-reinforced soil retaining wall", Geosynthetics International, 5(1-2), pp. 127166 (1998).

31. Saxena, S.K. and Lastrico, R.M. "Static properties of lightly cemented sand", Journal of the Geotechnical Engineering Division, 104(12), pp. 1449-1464 (1978).

32. Saxena, K., Reddy, R., and Avramidis, S. "Static behaviour of artificially cemented sand", Indian Geotechnical Journal, 18(2), pp. 110-141 (1989).

33. Hatami, K. and Bathurst, R.J. "Numerical model for reinforced soil segmental walls under surcharge loading", Journal of Geotechnical and Geoenvironmental Engineering, 132(6), pp. 673-684 (2006).

34. Collios, A., Delmas, P., Gourc, J.P., and Giroud, J.P. "Experiments on soil reinforcement with geotextiles", Use of Geotextiles for Soil Improvement. ASCE Proceedings of a Symposium Held in Portland, OR, USA pp. 53-73 (1980).

\section{Biographies}

Mehdi Derakhshandi received his BS degree in Civil Engineering from Isfahan University of Technology in 1998 and his MSc degree in Soil Mechanics and Foundation Engineering in 2000. He earned his PhD degree from Amirkabir University of Technology in 2006. He is currently an Assistant Professor of Science and Research Brunch, Islamic Azad University of Tehran. His research activities include cyclic behavior of soil materials by physical modelling and element testing.

Ghazale Rahmati obtained her BS degree in Civil Engineering and her MSc degree in Geotechnical Engineering from Arak University. The study of static and seismic performance of the geosynthetic reinforced 
soil systems is her research interest. She is currently a Geotechnical Engineer.

Mani Sadjadi is currently a PhD Candidate in Geotechnical Engineering at Research Brunch of Is- lamic Azad University, Tehran, Iran. His PhD thesis is on the performance of rocking soil-structure systems on improved soils. His research interests include geotechnical earthquake engineering, soil-structure interaction, and soil improvement. 